\title{
Reassessing access to intensive care using an estimate of the population incidence of critical illness
}

\author{
Allan Garland ${ }^{1,2,3^{*}}$ (D) Kendiss Olafson ${ }^{1}$, Clare D. Ramsey ${ }^{1,2}$, Marina Yogendranc ${ }^{3}$ and Randall Fransoo ${ }^{3}$
}

\begin{abstract}
Background: The consistently observed male predominance of patients in intensive care units (ICUs) has raised concerns about gender-based disparities in ICU access. Comparing rates of ICU admission requires choosing a normalizing factor (denominator), and the denominator usually used to compare such rates between subpopulations is the size of those subpopulations. However, the appropriate denominator is the number of people whose medical condition warranted ICU care. We devised an estimate of the number of critically ill people in the general population, and used it to compare rates of ICU admission by gender and income.

Methods: This population-based, retrospective analysis included all adults in the Canadian province of Manitoba, 2004-2015. We created an estimate for the number of critically ill people who warrant ICU care, and used it as the denominator to generate critical illness-normalized rates of ICU admission. These were compared to the usual population-normalized rates of ICU care.

Results: Men outnumbered women in ICUs for all age groups; population-normalized male:female rate ratios significantly exceed 0 for every age group, ranging from 1.15 to 2.10. Using critical-illness normalized rates, this male predominance largely disappeared; critically ill men and women aged $45-74$ years were admitted in equivalent proportions (critical-illness normalized rate ratios 0.96-1.01). While population-normalized rates of ICU care were higher in lower income strata $(p<0.001)$, the gradient for critical illness-based rates was reversed $(p<0.001)$.

Conclusions: Across a 30-year adult age span, the male predominance of ICU patients was accounted for by higher estimated rates of critical illness among men. People in lower income strata had lower critical-illness normalized rates of ICU admission. Our methods highlight that correct inferences about access to healthcare require calculating rates using denominators appropriate for this purpose.
\end{abstract}

Keywords: Critical illness, Intensive care units, Health care quality, access, and evaluation

\section{Background}

Disparities in health and healthcare delivery are ubiquitous [1-5]. Identifying and eliminating them has become a special focus of governments and international groups $[2,5,6]$. Studies showing that men outnumber women in ICUs throughout Europe [7-9] and North America [10-13] have raised concern about gender-related disparities in ICU access [14].

\footnotetext{
* Correspondence: agarland@hsc.mb.ca

${ }^{1}$ Department of Internal Medicine, University of Manitoba, 820 Sherbrook

Street, Winnipeg, MB R3A1R9, Canada

${ }^{2}$ Department of Community Health Sciences, University of Manitoba, Room

S113, 750 Bannatyne Avenue, Winnipeg, MB R3EOW3, Canada

Full list of author information is available at the end of the article
}

Identifying disparities in access to any healthcare interventions involves comparing rates of use between subgroups; that is, the quotient of the number of people who received the intervention to some normalizing factor (denominator). Although the most commonly used denominator is the size of the population, creating population-normalized rates, these rates can be misleading in assessing access to care $[15,16]$. Instead, the most appropriate denominator is the number of people whose medical condition warranted such care [17]. For ICU care, the correct denominator is the number of people who developed critical illness and were suitable candidates for ICU admission, producing critical 
illness-normalized rates. If men had higher critical illness rates but equal ICU access compared to women, their population-normalized rate would be higher, while their critical illness-normalized rates would be the same.

A method to estimate rates of critical illness in the population has been lacking [17]. Here we develop such a method and use it to evaluate equality of access to ICUs in the Canadian province of Manitoba, by gender and socioeconomic status (SES).

\section{Methods}

We used population-based data including hospital abstracts and vital statistics for all Manitobans, which reliably identify the existence and timing of ICU care [18, 19]. In 2016, Manitoba had a population of 1.34 million [20], covered by a single-payer health insurance system and serviced by 12 ICUs containing 82 Level 1 or Level 2 adult ICU beds [11, 21].

As will be discussed in greater detail, the new normalization factor sought to include all those who developed critical illness, excluding patients who "were not candidates" for ICU admission. We conceptualized people with critical illness as belonging to one of three categories: admitted to ICUs; died without admission to an ICU; and survived without ICU care. Our data only allow identification of the first two categories. We considered persons who were not candidates for ICU admission to be those formally identified as having received palliative care. Inpatient palliative care was recognized in hospital abstracts by ICD-10-CM palliative care diagnosis codes, or codes indicating that the patient's primary inpatient care team was the palliative care service. Outpatient palliative care was identified by specific codes in the provincial Long-Term Care and Homecare databases, or the provincial prescription drug database indicating medications supplied under a palliative care program.

We estimated the number of people $\geq 18$ years old in a given year who experienced critical illness suitable for ICU care as the number who were admitted to an ICU and/or died, excluding deaths for people in palliative care within 2 years of admission. We refer to this combined group as the Potential ICU Admission Pool. To avoid double counting of individuals, we operationally calculated the Potential ICU Admission Pool as the sum of all individuals admitted to an ICU and nonpalliative deaths among people not admitted to an ICU in that year (Additional file 1: Further Explication).

We assessed yearly rates of admission for Manitoba residents to provincial ICUs over 11 years, April 1, 2004-March 31, 2015. We compared yearly rates of ICU care using three different denominators: the population, obtained from the Manitoba Health Insurance Registry, producing population-normalized rates of ICU care; the Potential ICU Admission Pool, producing critical illness-normalized rates of ICU care; and the number of people who were hospitalized for reasons other than childbirth, obtained from provincial hospital abstracts, producing nonobstetrical hospitalization-normalized rates of ICU care. Obstetrical hospitalizations were excluded from the latter because their high numbers but low association with critical illness would distort assessment of gender-related differences in ICU care. In a sensitivity analysis, we excluded elective ICU admissions.

We assessed rates of ICU care stratified by age, gender, and SES. The SES was assessed as average household income within geographic dissemination areas [22], based on the 2011 Canadian census, divided into separate quintiles for urban and rural residents, plus a small group for whom income levels could not be calculated, mainly those in chronic care facilities and other institutions.

Comparison between proportions used Fisher's exact test. Unless otherwise indicated, comparisons were performed on data averaged over the 11 study years. Rates were age-adjusted using the direct method, with the general Manitoba population on March 31, 2015 as a reference. To make age-adjusted statistical comparisons between SES subgroups, we used grouped Poisson regression modeling of admission to ICUs with independent variables of the subgroups of interest and categorized age. Where indicated, Bonferroni adjustment was made for multiple comparisons. Analysis used SAS 9.0 (SAS Institute, Cary, NC, USA) and Stata 11.1 (Statacorp, College Station, TX, USA).

\section{Results}

The number of distinct individuals admitted yearly to ICUs rose over the study period, from 4078 to 4491 (Table 1). Overall, $61.0 \%$ of those admitted to ICUs were men. The population rose $1.40 \% /$ year, while nonobstetrical hospitalizations declined $0.03 \% /$ year. Nonpalliative deaths fell over time, while there was a rise in individuals admitted to ICUs who did not die in that year. The Potential ICU Admission Pool generally declined slightly over the study period (Table 1). As a fraction of the population, the Potential ICU Admission Pool rose steeply with age (Fig. 1).

The three different gender-specific, age-stratified rates of ICU admission show striking differences (Fig. 2, Additional file 1: Table S1). For both genders, the population-normalized rates rose steeply up to approximately age 79 years, and then plateaued or declined. Hospitalization-normalized rates showed a similar pattern, but with earlier peaks than the population-normalized rates. In contrast, critical illness-normalized rates of ICU care remained relatively constant until they began to decline after age 59 years for both genders.

Male:female ratios of the different rates clarify these effects (Fig. 3). As a fraction of the population, or of 
Table 1 Yearly counts of parameters used in calculating rates of ICU care, among Manitoba residents $\geq 18$ years old

\begin{tabular}{|c|c|c|c|c|c|c|c|}
\hline Year & $\begin{array}{l}\text { Unique people } \\
\text { admitted to ICUs }\end{array}$ & Population & $\begin{array}{l}\text { Nonobstetrical } \\
\text { hospitalizations }\end{array}$ & $\begin{array}{l}\text { Palliative deaths, }{ }^{a} n \\
\text { (\% total deaths) }\end{array}$ & $\begin{array}{l}\text { Nonpalliative } \\
\text { deaths }^{\mathrm{a}}\end{array}$ & $\begin{array}{l}\text { Admitted to ICU and } \\
\text { did not die that year }\end{array}$ & $\begin{array}{l}\text { Potential ICU } \\
\text { Admission Pool }\end{array}$ \\
\hline $2004 / 05$ & 4078 & 886,141 & 59,179 & $1738(17.6)$ & 8140 & 3092 & 11,232 \\
\hline 2005/06 & 4111 & 891,635 & 59,348 & $2329(24.2)$ & 7312 & 3381 & 10,693 \\
\hline 2006/07 & 4186 & 897,855 & 58,624 & 3085 (31.7) & 6662 & 3537 & 10,199 \\
\hline 2007/08 & 4286 & 910,110 & 57,449 & 3075 (31.7) & 6619 & 3587 & 10,206 \\
\hline 2008/09 & 4241 & 921,181 & 58,427 & $3413(34.7)$ & 6411 & 3659 & 10,070 \\
\hline 2009/10 & 4340 & 936,779 & 59,721 & 3681 (37.8) & 6051 & 3784 & 9835 \\
\hline 2010/11 & 4388 & 952,989 & 59,408 & 3796 (38.1) & 6156 & 3870 & 10,026 \\
\hline 2011/12 & 4401 & 969,591 & 59,558 & 3823 (38.7) & 6062 & 3893 & 9955 \\
\hline 2012/13 & 4465 & 988,801 & 58,562 & $4104(41.8)$ & 5717 & 4042 & 9759 \\
\hline 2013/14 & 4443 & $1,005,477$ & 57,657 & $4124(41.8)$ & 5738 & 4004 & 9742 \\
\hline 2014/15 & 4491 & $1,018,590$ & 58,942 & $4273(40.4)$ & 6291 & 4053 & 10,344 \\
\hline $\begin{array}{l}\text { Unweighted } \\
\text { average }\end{array}$ & 4312 & 943,559 & 58,807 & 3404 (34.4) & 6469 & 3718 & 10,187 \\
\hline Males (\%) & 61.0 & 48.8 & 46.2 & 50.7 & 49.0 & 61.6 & 53.6 \\
\hline
\end{tabular}

ICU high intensity (Level 1 and Level 2) intensive care units in Manitoba

${ }^{\text {a }}$ People who died and were recorded to have been in a palliative care program within the 2 years prior to death

hospitalized people, men had substantially higher rates than women for all age groups. However, when assessed relative to the Potential ICU Admission Pool, this excess of men mostly disappeared. With this denominator: there was a 7-14 absolute percentage excess of women in ICUs for ages 18-44 years; men and women aged 4574 years were admitted in similar proportions; and for age $\geq 75$ years, rates of ICU admission for men increasingly exceeded those for women. In absolute terms, approximately $80 \%$ of the total amount by which men outnumbered women in Manitoba ICUs occurred in the age range 45-74 years (Additional file 1: Table S2).

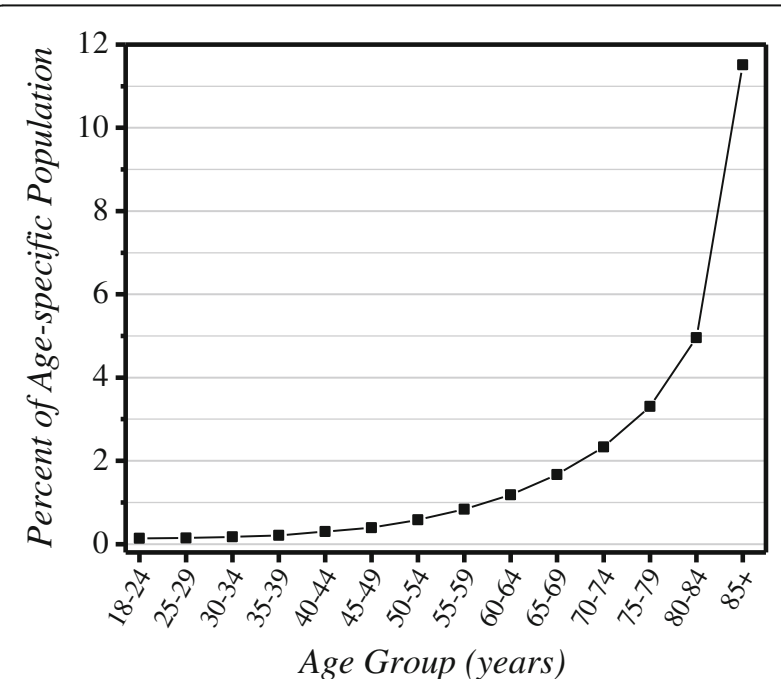

Fig. 1 Size of the Potential ICU Admission Pool as a fraction of the population, by age. Data are unweighted averages over all 11 years
Likewise, for analysis of ICU care by SES, the pattern was dependent on the normalizing factor used. Population-normalized rates of ICU care (Fig. 4, left panel) were higher for those with lower incomes and highest among institutionalized people. Both of these findings were reversed for critical illness-normalized rates of ICU admission (Fig. 4, right panel).

For the sensitivity analysis we excluded ICU admissions contained within elective hospital admissions. These are largely planned ICU care after certain elective surgical procedures, most commonly cardiac surgeries. This reduced the number of people admitted yearly to ICUs by $20.6 \%$, and the Potential ICU Admission Pool by $7.4 \%$. It did not appreciably alter the male:female ICU admission rate ratios (Additional file 1: Figure S2). This modification also did not alter the effects for SES (data not shown).

\section{Discussion}

In this study, we developed an approximation of the incidence rate of critical illness in populations, and used it to show that across a 30-year adult age span the observed male predominance of ICU patients [7-13] was accounted for by higher rates of critical illness among men. Thus, concern that the male predominance indicates that women are disadvantaged with regard to ICU access [14] appears to be largely unfounded. Population-normalized rates are suitable for assessing healthcare utilization, but not healthcare access. For that purpose, the most appropriate denominator is the number of people who warranted such care. No prior studies of disparities in critical illness have performed such an 

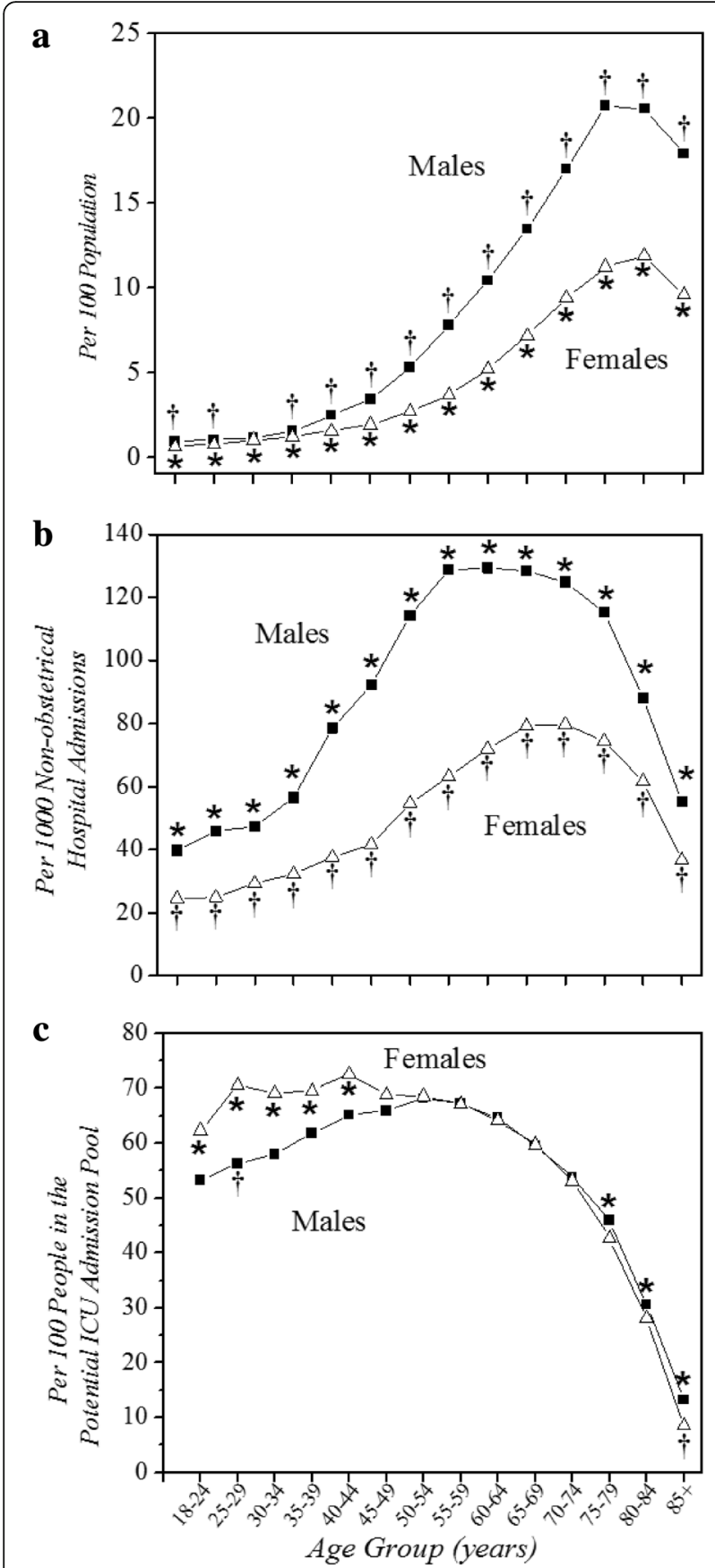

Fig. 2 Gender-specific rates of ICU care, by age. a Normalized by population. b Normalized by nonobstetrical hospitalizations. c Normalized by Potential ICU Admission Pool. Data are unweighted averages over all 11 years. ${ }^{*} p<0.05$, comparison of males to females for age category with no adjustment for multiple comparisons. $t p<0.05$, comparison of males to females for age category with Bonferroni adjustment for 42 comparisons. ICU intensive care unit

analysis, [23] although Fransoo et al. found that higher population-normalized rates of cardiac catheterization among men are accounted for by differences in rates of underlying coronary artery disease [16].

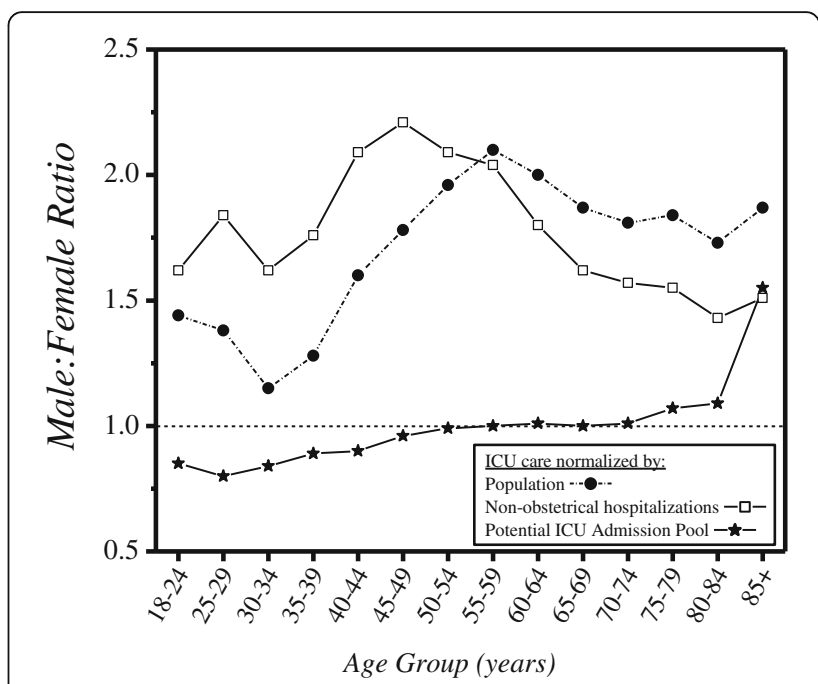

Fig. 3 Male:female ratios of three different rates of ICU care, by age. Data are unweighted averages over all 11 years. ICU intensive care unit

We speculate that higher critical illness-normalized rates of ICU admission for women in younger age groups reflect the known excess among men of out-of-hospital deaths from trauma and violence [24]. Lower critical illness-normalized rates for older females could be due to a lower desire for aggressive medical care among elderly women than elderly men [25].

We computed hospitalization-based rates of ICU admission to compare with a study from British Columbia which reported that male:female ratios for hospitalization-based rates were near unity for most age groups [12]. That finding suggested that the male predominance seen in population-based rates was due to prehospital factors. However, in Manitoba the male predominance of hospitalization-based rates and population-based rates were similar overall (Fig. 3). While the reason for this difference is not clear, our data included the entire adult population of the province, while the British Columbia result derived from a single hospital.

Our second major finding was lower rates of ICU admission among critically ill persons in lower income strata. This mirrors work showing reduced access to healthcare services among the poor in developed countries, regardless of whether or not, like Canada, they provide universal, government-funded medical care $[1,26]$. Analogous to studies of hospitalizations in France [27] and England [28], we found higher population-based rates of ICU admission in lower SES strata. The reversal of this gradient for critical illness-normalized rates again demonstrates the importance of choosing a denominator appropriate for assessing access to healthcare.

Differences such as these, in critical illness-normalized rates between subgroups, may result from differences in 


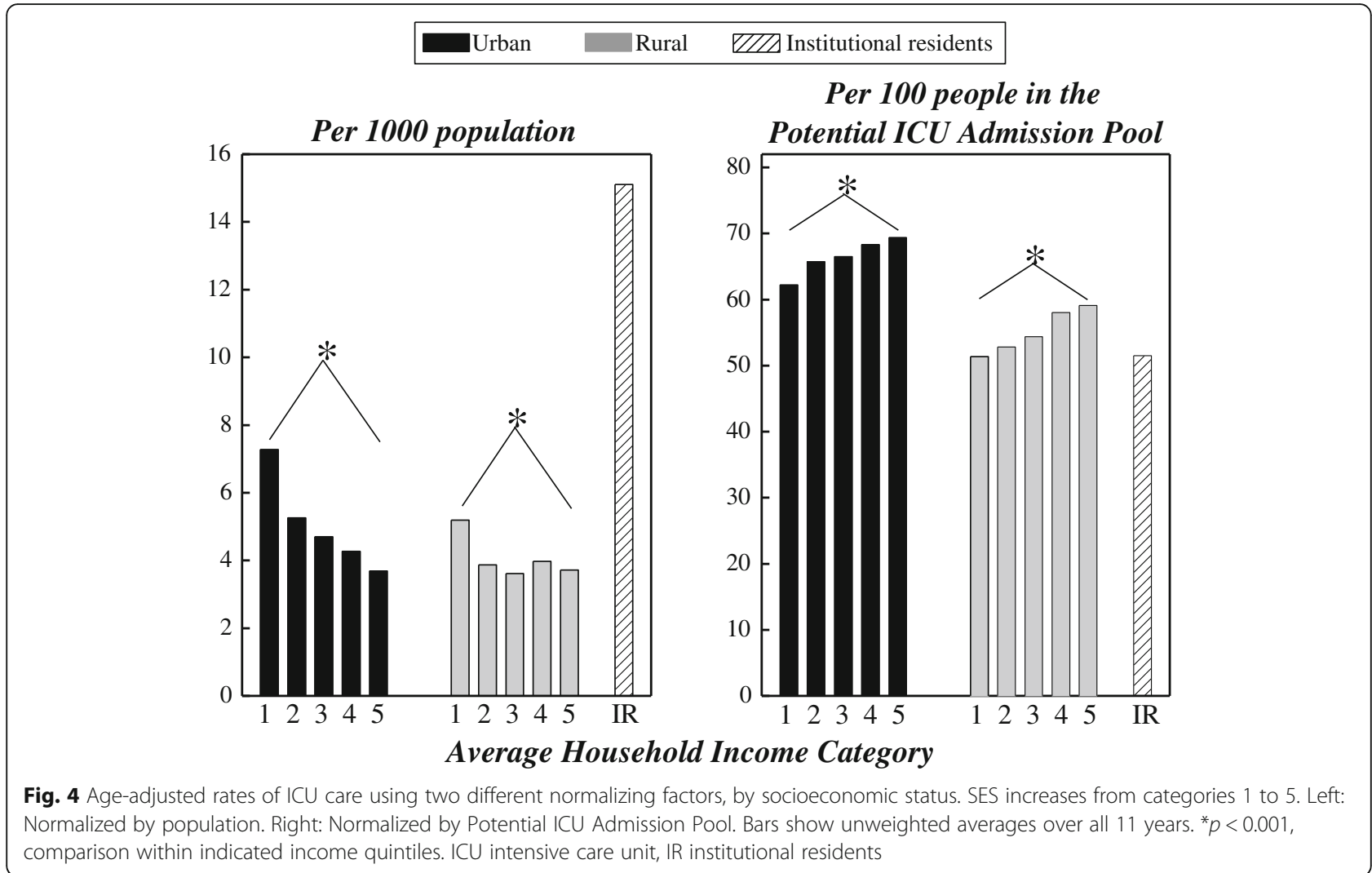

any of the following seven sequential events that define the pathway from onset of illness until ICU entry: (1) propensity toward critical illness; (2) early recognition of illness by patients; (3) willingness of patients to seek initial medical care; (4) availability of and initial access to the healthcare system, including outpatient services and hospital emergency departments; (5) admission to hospital; (6) willingness of patients for aggressive medical care as provided in ICUs; and (7) admission to the ICU. Of particular interest as regards possible gatekeeper bias is that triage decisions made by various medical gatekeepers come into play in items 4, 5, and 7. Although our analysis using critical illness-normalized rates of ICU admission is not consistent with gender-based bias in triage decisions by gatekeepers, we cannot exclude the possibility of such bias as regards SES.

Our new normalizing factor is the first to provide an estimate of the incidence of critical illness in populations [17]. While we recognize that it is only an approximation of the true underlying rate of critical illness, it nonetheless is a more appropriate denominator for assessing inequalities in ICU access than is the population count. In addition, that the male:female ratio for a 30 -year age range is not only constant, but essentially unity, lends a degree of face validity to the Potential ICU Admission Pool as the appropriate normalizing factor for assessing ICU access. Prior evaluations of the incidence of various types of critical illness have used data limited to patients admitted to hospitals or ICUs, and/or with specific types of critical illness [29-34].

The main strength of our work is the reduction of potential biases by assessing an entire provincial population over 11 years. Its main limitation is that it depends on the validity of our estimate for the number of people who experienced critical illness each year and were suitable candidates for ICU admission. Each component warrants discussion and has limitations.

First, we pragmatically chose to accept that patients were critically ill if they were admitted to a high-intensity ICU. In the absence of evidence-based guidelines for what constitutes illness severe enough to warrant ICU admission [35], and with obvious differences in admission thresholds between ICUs, this choice can be criticized. However, it is challenging to devise and operationalize a better alternative.

Second is the concept that all deaths are associated with critical illness, even if that illness may have been very brief (e.g., traumatic death in the field). We justify this choice by recognizing that if such a person had been close to death at the time of discovery, rather than being dead, they might have survived long enough to be admitted to an ICU. We note that the fraction of all deaths that were palliative rose from 18 to $40 \%$ over the 11-year study interval. This may lead to concern that changing gender 
fractions within subcategories of death might influence our findings about the male:female ratio of ICU admissions. But in fact the male fractions of palliative deaths varied narrowly over the 11 years of the study (49.3$51.8 \%)$, as did the male fraction in ICUs (59.7-62.2\%). We also note that the results were not altered in a sensitivity analysis that excluded from consideration elective ICU admissions, as commonly occur in Manitoba after elective cardiac and other high-risk surgical procedures.

Third are individuals who survived critical illness without ICU care. Although true critical illness that resolved without any medical care is likely extraordinarily rare, the number who survived with care provided outside of ICUs may not be negligible [36]. That our data lack information to estimate the size of this subset is the primary limitation of using the Potential ICU Admission Pool as a normalizing factor; however, it may be the smallest of the three main categories of critically ill people [37].

Fourth is whether and how to exclude critically ill people who "were not candidates" for ICU care. This includes critically ill people who: (i) died before they could get to an ICU; (ii) did not desire ICU care; and (iii) desired ICU care but were not accepted into the ICU by those with gatekeeping authority. While at first it seems desirable to exclude these subgroups, doing so would eliminate the ability to identify inequalities that can influence those issues, resulting in selection bias for our analysis [38]. Regarding subgroup i, economically disadvantaged persons and those in remote communities may have less access to timely care for catastrophic illness, causing higher rates of death. Subgroup ii likewise has potential for bias, as there are inequalities in access to palliative care [39]. Also, patients' decisions to forego aggressive care are substantially influenced by their physicians [40], who can make care recommendations biased by factors such as gender without realizing it [41]. Also, as subgroup iii represents subjective, value-based decisions by gatekeepers, it is also prone to variation and bias. The only members of subgroups i-iii we can identify are those identified as having received palliative care in administrative data sources. While it would be desirable to have validated measures for all individuals who were not candidates for ICU admission by virtue of receiving symptom-focused end-of-life care, methods to do this using administrative data do not currently exist $[42,43]$. What is known is that the use of ICD-9 diagnosis coding of palliative care among inpatients fails to identify many patients who actually received such care $[44,45]$, with such false-negatives being more common in outpatients than inpatients, and in the oldest age groups [42]. Indeed, the lower critical illness-normalized rates of ICU admission we observed in lower SES strata (Fig. 2c) could be due, in part, to underestimating decisions to limit aggressive care for those groups [39]. Thus, while pragmatic, this aspect of our calculation of the Potential ICU Admission Pool is also admittedly imperfect.

Indeed, any calculation of the number of people who experienced critical illness each year and were candidates for ICU admission would only be an approximation. Going beyond our approximation could involve the combination of: manual review of individual medical records including those pre hospital and in hospital, as well as autopsy and other death-related records for out-of-hospital deaths; and consensus definitions of what constitutes critical illness, candidates for ICU care, and avoidable deaths. Unfortunately, the latter do not exist or are poorly developed. There is not even agreement about what constitutes critical illness, as evidenced by the paucity of attempts over the past 30 years to devise a set of general ICU triage criteria $[35,46]$, and by the large variation, seen at multiple levels, in observed ICU admission patterns [47-51]. As for manual chart reviewing, its validity is limited, as indicated by poor agreement between reviewers [52-54]. While performing such time-consuming, labor-intensive manual reviews would render such methods incapable of use in large databases such as administrative data, manual chart reviewing would be feasible as an exercise to further validate our methods. Ultimately, we recognize that our method carries risk of unknown biases.

To assess the robustness of our findings, we conducted sensitivity analyses using modified versions of the Potential ICU Admission Pool. The first analysis used a denominator calculated as the sum of all deaths plus ICU admissions, and therefore it did not exclude deaths among those in palliative care. The second was normalized by total deaths, reasoning that this metric should track, although not equal, the number of critically ill people in the population. This latter normalization has been used before to evaluate medical resource use for critically ill people [55]. For assessing gender differences in ICU care, these two alternative denominators also dramatically reduced the male:female ratio evident in population-based rates, although to a lesser degree compared to our critical illness-normalized rates (Additional file 1: Figure S1). The similarities of findings between denominators that did and did not exclude deaths of those in palliative care provide assurance that our findings are not a result of differences in palliative care use between subgroups.

\section{Conclusions}

We have demonstrated that most of the male predominance of ICU admission is a consequence of men having a higher rate of critical illness than women. The new factor we developed, the Potential ICU Admission Pool, was designed to allow for more appropriate analysis and comparison of ICU access. In light of the considerations 
detailed, we recognize that there is no unimpeachable method of estimating the number of people who should be admitted to ICUs. Accordingly, in devising this factor, we made a number of pragmatic choices, which while imperfect, provide a method for assessing ICU access that is superior to those that have been used to date. In comparison to population-normalized rates, critical illness-normalized rates led to very different conclusions about rates of ICU admission by gender and income. As this is the first effort using our new methodology, future studies are needed both for confirmation of our findings and to further explore these associations.

\section{Additional file}

Additional file 1: Further explication of the Potential ICU Admission Pool and critical illness-normalized rates of ICU care. Table S1.

Comparison of three different rates of ICU care, by gender and age. Data are unweighted averages over all 11 years, at the level of individuals. $p$ values compare average rates for women vs men. Table S2. Estimated age composition of male predominance of ICU admission in Manitoba for 2010. Figure S1. Comparison of male:female ratios of four different rates of ICU care, by age. Data are unweighted averages over all 11 years. Figure S2. Comparison of male:female ratios of four different rates of ICU care, by age. Data are unweighted averages over all 11 years (DOC $130 \mathrm{~kb}$ )

\section{Abbreviations}

ICD: International Classification of Diseases; ICU: Intensive care unit; SES: Socioeconomic status

\section{Acknowledgements}

The authors acknowledge the Manitoba Centre for Health Policy for use of data contained in the Population Health Research Data Repository. The results and conclusions are those of the authors and no official endorsement by the Manitoba Centre for Health Policy, Manitoba Health, or other data providers is intended or should be inferred.

\section{Funding}

The work was funded by a research grant from the Department of Health of the Province of Manitoba, which had no role in study design, analysis, or interpretation of the data, or in writing of the manuscript.

\section{Availability of data and materials}

The authors are not the custodian for the data used in this study, and therefore are unable to provide access to it. The data for this study are part of the Population Health Research Data Repository at the Manitoba Centre for Health Policy (the custodian), from which there is restricted availability.

\section{Authors' contributions}

AG originated the concept for this study. MY, AG, and RF conducted the analyses. All authors planned the study design, contributed to the interpretation of the data, and drafted and approved the submitted manuscript. AG had full access to all of the data in the study and takes responsibility for the integrity of the data and the accuracy of the data analysis.

\section{Ethics approval and consent to participate}

This study was approved by the University of Manitoba Health Research Ethics Board (Approval \#HS11780) and the Manitoba Health Information Privacy Committee.

Not applicable, as this study used existing, de-identified data.

\section{Consent for publication}

Not applicable.

\section{Competing interests}

The authors declare that they have no competing interests.

\section{Publisher's Note}

Springer Nature remains neutral with regard to jurisdictional claims in published maps and institutional affiliations.

\section{Author details}

${ }^{1}$ Department of Internal Medicine, University of Manitoba, 820 Sherbrook Street, Winnipeg, MB R3A1R9, Canada. ${ }^{2}$ Department of Community Health Sciences, University of Manitoba, Room S113, 750 Bannatyne Avenue, Winnipeg, MB R3E0W3, Canada. ${ }^{3}$ Manitoba Centre for Health Policy, University of Manitoba, Room 408, 727 McDermot Avenue, Winnipeg, MB R3E3P5, Canada.

Received: 1 February 2018 Accepted: 20 July 2018

Published online: 20 August 2018

\section{References}

1. van Doorslaer E, Masseria C, Koolman X, The OECD Health Equity Research Group. Inequalities in access to medical care by income in developed countries. Can Med Assoc J. 2006;174(2):177-83.

2. Gwatkin DR. Health inequalities and health of the poor: what do we know? What can we do? Bull World Health Organ. 2000;78(1):3-18.

3. Bleich $\mathrm{S}$, Jarlenski M, Bell C, LaVeist T. Health inequalities: trends, progress, and policy. Annu Rev Public Health. 2012;33:7-40.

4. Sirven N, Or Z. Mannheim Research Institute for the Economics of Aging. Disparities in Regular Health Care Utilisation in Europe. http://mea.mpisoc. mpg.de/uploads/user_mea_discussionpapers/1128_231-10.pdf. Accessed 1 Aug 2018.

5. Smedley B, Stith A, Nelson A, editors. Unequal treatment: confronting racial and ethnic disparities in health care. Washington, DC: National Academies Press; 2003.

6. Patient protection and affordable care act: United States HR 3590. http:// www.govtrack.us/congress/bills/111/hr3590/text. Accessed 1 Aug 2018.

7. Valentin A, Jordan B, Lang T, Hiesmayr M, Metnitz P. Gender-related differences in intensive care: a multiple-center cohort study of therapeutic interventions and outcome in critically ill patients. Crit Care Med. 2003;31(7): 1901-7

8. Luyt C, Combes A, Aegerter P, Guidet B, Trouillet J, Gibert C, Chastre J. Mortality among patients admitted to intensive care units during weekday day shifts compared with "off" hours. Crit Care Med. 2007;35(1):3-11.

9. Neavyn MJ, Boyer EW, Bird SB, Babu KM. Sodium acetate as a replacement for sodium bicarbonate in medical toxicology: a review. J Med Toxicol. 2013:9(3):250-4

10. Laupland KB. Population-based epidemiology of intensive care: critical importance of ascertainment of residency status. Crit Care. 2004;8:R431-6.

11. Garland A, Olafson K, Ramsey C, Yogendran M, Fransoo R. Epidemiology of critically ill patients in intensive care units: a population-based observational study. Crit Care. 2013;17(5):R212.

12. Dodek P, Kozak J, Norena M, Wong H. More men than women are admitted to 9 intensive care units in British Columbia. J Crit Care. 2009;24(4):630. e631-8.

13. Fowler RA, Sabur N, Li P, Juurlink DN, Pinto R, Hladunewich MA, Adhikari NKJ, Sibbald WJ, Martin C. Sex-and age-based differences in the delivery and outcomes of critical care. Can Med Assoc J. 2007;177(12):1513-9.

14. Bierman AS. Research: sex matters: gender disparities in quality and outcomes of care. Can Med Assoc J. 2007:177(12):1520-1.

15. Magner D, Mirocha J, Gewertz B. Regional variation in the utilization of carotid endarterectomy. J Vasc Surg. 2009;49(4):893-901.

16. Fransoo R, Martens P, Prior H, Burland E, Chateau D, Katz A, The Need To Know Team. Age difference key to understanding gender difference in cardiac intervention rates after acute myocardial infarction. Healthcare Policy. 2010;6(1):88-103.

17. Okamoto VN, Rubenfeld GD. Attending to the lightness of numbers: toward the understanding of critical care epidemiology. Crit Care. 2004;8:422-4.

18. Garland A, Yogendran M, Olafson K, Scales DC, McGowan K-L, Fransoo R. The accuracy of administrative data for identifying the presence and timing of admission to intensive care units in a Canadian Province. Med Care. 2012 50:e1-6. 
19. Fransoo R, Yogendran M, Olafson K, Ramsey C, McGowan K-L, Garland A. Constructing episodes of inpatient care: data infrastructure for populationbased research. BMC Med Res Methodol. 2012;12(1):133.

20. Manitoba Health. Manitoba Population Report: June 1, 2010. https://www. gov.mb.ca/health/population/pr2010.pdf. Accessed 28 Jan 2018.

21. Haupt MT, Bekes CE, Brilli RJ, Carl LC, Gray AW, Jastremski MS, Naylor DF, Rudis M, Spevetz A, Wedel SK, et al. Guidelines on critical care services and personnel: recommendations based on a system of categorization of three levels of care. Crit Care Med. 2003;31(11):2677-83.

22. Postal Code Conversion File (PCCF), Reference Guide. Ottawa: Statistics Canada; 2013. http://www.statcan.gc.ca/pub/92-154-g/92-154-g2013001eng.pdf. Accessed 1 Aug 2018.

23. Soto G, Martin G, Gong M. Healthcare disparities in critical illness. Crit Care Med. 2013;41(12):2784-93.

24. Canadian Institute for Health Information. 2009 Report: Major Injury in Canada. http://publications.gc.ca/collections/collection_2010/icis-cihi/H1154-2009-eng.pdf. Accessed 1 Aug 2018.

25. Philippart F, Vesin A, Bruel C, Kpodji A, Durand-Gasselin B, Garçon P, LevySoussan M, Jagot JL, Calvo-Verjat N, Timsit JF, et al. The ETHICA study (part I): elderly's thoughts about intensive care unit admission for life-sustaining treatments. Intensive Care Med. 2013;39(9):1565-73.

26. Danis M, Linde-Zwirble W, Astor A, Lidicker J, Angus D. How does lack of insurance affect use of intensive care? A population-based study. Crit Care Med. 2006;34(8):2043-8.

27. Tuppin P, Drouin J, Mazza M, Weill A, Ricordeau P, Allemand H. Hospitalization admission rates for low-income subjects with full health insurance coverage in France. Eur J Pub Health. 2011;21(5):560-6.

28. Parslow R, Tasker R, Draper E, Parry G, Jones S, Chater T, Thiru K, McKinney $P$, Paediatric Intensive Care Audit Network. Epidemiology of critically ill children in England and Wales: incidence, mortality, deprivation and ethnicity. Arch Dis Child. 2009;94(3):210-5.

29. Angus DC, Linde-Zwirble WT, Lidicker J, Clermont G, Carcillo J, Pinsky MR. Epidemiology of severe sepsis in the United States: analysis of incidence, outcome, and associated costs of care. Crit Care Med. 2001;29(7):1303-10.

30. Annane D, Aegerter P, Jars-Guincestre MC, Guidet B, CUB-Rea Network. Current epidemiology of septic shock. Am J Respir Crit Care Med. 2003; 168(2):165-72.

31. Behrendt CE. Acute respiratory failure in the United States. Chest. 2000; 118(4):1100-5.

32. Cooke C, Erickson S, Eisner M, Martin G. Trends in the incidence of noncardiogenic acute respiratory failure: the role of race. Crit Care Med. 2012:405:1532-8.

33. Dombrovskiy V, Martin A, Sunderram J, Paz HL. Facing the challenge: decreasing case fatality rates in severe sepsis despite increasing hospitalizations. Crit Care Med. 2005;33(11):2555-62.

34. Sundararajan V, Maclsaac C, Presneill JJ, Cade JF, Visvanathan K. Epidemiology of sepsis in Victoria, Australia. Crit Care Med. 2005;33(1):71-80.

35. Task Force of the American College of Critical Care Medicine, Society of Critical Care Medicine. Guidelines for intensive care unit admission, discharge, and triage. Crit Care Med. 1999;27(3):633-8.

36. Sinuff T, Kahnamoui K, Cook D, Luce J, Levy M, Values Ethics and Rationing in Critical Care Task Force. Rationing critical care beds: a systematic review. Crit Care Med. 2004;32(7):1588-98.

37. Joynt GM, Gomersall CD, Tan P, Lee A, Cheng CA, Wong EL. Prospective evaluation of patients refused admission to an intensive care unit: triage, futility and outcome. Intensive Care Med. 2001;27(9):1459-65.

38. Braithwaite RS. Risk adjustment for quality measures is neither binary nor mandatory. JAMA. 2018;319(20):2077-8.

39. Canadian Hospice Palliative Care Association. Fact Sheet: Hospice Palliative Care in Canada. http://www.chpca.net/resource_doc_library/Fact_Sheet_ HPC_in_Canada.pdf. Accessed 1 Aug 2018.

40. Garland A, Connors AF Jr. Physicians' influence over decisions to forego life support. J Palliat Med. 2007;10(6):1298-305.

41. Borkhoff CM, Hawker GA, Kreder HJ, Glazier RH, Mahomed NN, Wright JG. Patients' gender affected physicians' clinical decisions when presented with standardized patients but not for matching paper patients. J Clin Epidemiol. 2009;62:527-41.

42. Tanuseputro P, Budhwani S, Bai YQ, Wodchis WP. Palliative care delivery across health sectors: a population-level observational study. Palliat Med. 2017:31(3):247-57.
43. Downar J, Sibbald R, Lazar N. Ethical considerations for classifying patients as 'palliative' when calculating hospital standardised mortality ratios. J Med Ethics. 2010;46(7):387-90.

44. Qureshi Al, Adil MM, Suri MF. Rate of utilization and determinants of withdrawal of care in acute ischemic stroke treated with thrombolytics in USA. Med Care. 2013;51(12):1094-100.

45. Hua M, Li G, Clancy C, Morrison RS, Wunsch H. Validation of the V66.7 code for palliative care consultation in a single Academic Medical Center. J Palliat Med. 2017;20(4):372-7.

46. Kim S-H, Chany CW, Olivares M, Escobar G. ICU admission control: an empirical study of capacity allocation and its implication on patient outcomes. Manag Sci. 2015;61(1):19-38.

47. Azoulay E, Pochard F, Chevret S, Vinsonneau C, Garrouste M, Cohen Y, Thuong M, Paugam C, Apperre C, De Cagny B, et al. Compliance with triage to intensive care recommendations. Crit Care Med. 2001:29(11):2132-6.

48. Truog R, Brock DW, Cook D, Danis M, Luce J, Rubenfeld G, Levy M, Task Force on Values Ethics and Rationing in Critical Care (VERICC). Rationing in the intensive care unit. Crit Care Med. 2006;34(4):958-63.

49. Gershengorn HB, Iwashyna TJ, Cooke CR, Scales DC, Kahn JM, Wunsch H. Variation in use of intensive care for adults with diabetic ketoacidosis. Crit Care Med. 2012;40(7):2009-15.

50. Stelfox HT, Hemmelgarn BR, Bagshaw SM, Gao S, Doig CJ, Nijssen-Jordan C, Manns B. Intensive care unit bed availability and outcomes for hospitalized patients with sudden clinical deterioration. Arch Intern Med. 2012;172(6): 467-74.

51. Valley TS, Zahuranec DB, Garland A, Fagerlin A, Iwashyna TJ. Clinical estimates of patient benefit from ICU care are influenced by logically irrelevant factors: a randomized study. Am J Res Crit Care Med. 2018;197: A6289.

52. Haywood RA, Hofer TP. Estimating hospital deaths due to medical errors. JAMA. 2001;286(4):415-20.

53. Thomas EJ, Studdert DM, Brennan TA. The reliability of medical record review for estimating adverse event rates. Ann Intern Med. 2002;136(11): 812-6.

54. Wenner JB, Norena M, Khan N, Palepu A, Ayas NT, Wong H, Dodek PM. Reliability of intensive care unit admitting and comorbid diagnoses, race, elements of acute physiology and chronic health evaluation II score, and predicted probability of mortality in an electronic intensive care unit database. J Crit Care. 2009;24:401-7.

55. Wiener RS, Welch HG. Trends in the use of the pulmonary artery catheter in the United States, 1993-2004. JAMA. 2007:298(4):423-9.

Ready to submit your research? Choose BMC and benefit from

- fast, convenient online submission

- thorough peer review by experienced researchers in your field

- rapid publication on acceptance

- support for research data, including large and complex data types

- gold Open Access which fosters wider collaboration and increased citations

- maximum visibility for your research: over $100 \mathrm{M}$ website views per year

At $\mathrm{BMC}$, research is always in progress.

Learn more biomedcentral.com/submissions 